\title{
Tarımsal Atıktan Elde Edilen Aktif Karbon Destekli Co-B Katalizörü Varlığında Sodyum Borhidrürün Metanolizi
}

\author{
Mustafa KAYA*, Mesut BEKİROĞULLARI \\ Siirt Üniversitesi, Mühendislik Fakültesi, Kimya Mühendisliği Bölümü, Siirt, TÜRKİYE
}

\begin{tabular}{ll}
\hline \multicolumn{1}{c}{ Geliş Tarihi/Received: 19.11 .2018} & Kabul Tarihi/Accepted: 26.02 .2019 \\
\hline ORCID ID (Yazar surasma göre / by author order) & \\
\hline (D) orcid.org/0000-0002-0622-3163 (D) orcid.org/0000-0001-9539-9234 & \\
\hline *Sorumlu Yazar/Corresponding Author: mustafakaya@siirtedu.tr
\end{tabular}

*Sorumlu Yazar/Corresponding Author: mustafakaya@siirt.edu.tr

Öz: Bu çalışmada, tarımsal atık olan Siirt fıstığı kabuğundan elde edilen aktif karbon kullanılarak destekli Co-B katalizörü sentezlenmiş ve bu katalizör hidrojen eldesinde kullanılmıştır. Siirt yöresinin en önemli tarımsal gelir kaynaklarının başında Siirt fistığ 1 gelmektedir. Fistık işlendikten sonra geriye kalan fistık kabuğu ise tarımsal atık olarak kabul edilmekte olup, bu atığın etkin bir şekilde kullanılması ise oldukça önem arz etmektedir. Aktif karbon destekli Co-B katalizörü, sodyum borhidrür

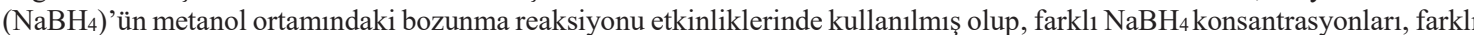
katalizör miktarları ve farklı sıcaklıklar varlığında deneyler yapılarak etkinlikleri incelenmiştir. Çalışmada; $30{ }^{\circ} \mathrm{C}$ sıcaklıktaki aynı $\mathrm{NaBH}_{4}$ konsantrasyonun, farklı katalizör miktarları kullanılarak yapılan metanoliz deneylerinde, katalizör miktarı arttıkça reaksiyonun tamamlanma süresi kısalmakta ve hidrojen üretim hızının artmakta olduğu gözlemlenmiştir. Aktif karbon destekli Co-B katalizörü varlığında metanoliz deneylerinin farklı sıcaklık (30-60 $\left.{ }^{\circ} \mathrm{C}\right)$ etkinlikleri incelendiği zaman ise sıcaklığın artmasıyla reaksiyon hızındaki artışın da belirgin bir şekilde olduğu görülmüştür. Bunun yanı sıra tarımsal atıkların işlenerek katalizörlerde destek maddesi olarak kullanımının katalizör etkinliğini arttırdığı tespit edilmiştir. Son olarak; bu deney sonuçlarından elde edilen veriler kullanılarak reaksiyon modeli çıkarılmış olup, buna bağlı olarak bir ampirik formül türetilmiş ve bundan sonra yapılacak deneylerin sonucunu teorik olarak da elde edilebilecek denkleme ulaşılmıştır. Yapılan bu çalışma sayesinde tarımsal atık olarak kabul edilen Siirt fıstığ 1 kabuğu etkin bir şekilde değerlendirilmiş olup, bu atık malzeme katma değeri yüksek olan bir ürüne dönüştürülmüştür.

Anahtar Kelimeler: Tarımsal atık, Siirt fistı ̆̆ kabuğu, sodyum borhidrür, Co-B, metanoliz

\section{Sodium Borohydride Methanolysis in the Presence of a Carbon Supported Co-B Catalysts Produced from Agricultural Waste}

\begin{abstract}
In this study, Co-B catalyst was synthesized by using activated carbon obtained from Siirt pistachio shell, which is an agricultural waste, and this catalyst was used in hydrogen production process. Siirt pistachio is one of the most important agricultural income sources of Siirt region. After processing pistachio, the remaining pistachio shell is considered as agricultural waste, and the efficient use of this waste is of great importance. Activated carbon supported Co-B catalyst was used in the reduction of $\mathrm{NaBH}_{4}$. In order to define the kinetics of the catalyst, different $\mathrm{NaBH}_{4}$ concentrations, catalyst concentrations and temperatures were studied. In the methanolysis experiments using the same $\mathrm{NaBH} 4$ concentration at $30{ }^{\circ} \mathrm{C}$ with different catalyst amounts, the completion time of the reaction was shortened as the amount of catalyst increased, and the rate of hydrogen production was observed to be increasing. In the presence of activated carbon-supported Co-B catalyst, when different temperature $\left(30-60^{\circ} \mathrm{C}\right)$ activities of methanolysis experiments were examined, it was observed that the reaction rate increased significantly with increasing temperature. It was found that agricultural waste can be efficiently used to produce support material for the production of high capacity catalysts. Finally, the reaction pattern was extracted using the data from the results of this experiment, whereby an empirical formula was derived, and the result of the future experiments can theoretically be obtained with this equation. As a result of this study, Siirt pistachio shell, considered as agricultural waste, is effectively processed and converted into a product with high added value.
\end{abstract}




\section{Giriş}

Fosil yakıtlarının zamanla azalmasının yanı sıra bu yakıtların kullanımı sonucu çevreye yayılan; yanmamış hidrokarbon, is (kurum), koku, karbon monooksit (CO) ve sera etkisi yapan karbon dioksit $\left(\mathrm{CO}_{2}\right)$ gibi zehirli atıklar, ekolojik dengeyi bozarak insan sağlığına vermektedir. Gelecekte çevre ve enerji sorunlarını aşacak alternatif temiz enerji kaynakları, günümüzde halen araştırılmakta olup bu enerji kaynaklarının en önemlilerinden birisi olarak hidrojen $\left(\mathrm{H}_{2}\right)$ ön plana çıkmaktadır (İzgi ve ark., 2017). Hidrojen; kimyasal enerjinin elektrik enerjisine, 1sıya ve suya çevrildiği Proton Değişim Membranı (PEM) yakıt pilleri için ideal bir yakıt olup; fosil yakıtlarından çevreye salınan zehirli gazlar ve kirletici gibi etkenler oluşmaz. Ancak $\mathrm{H}_{2}$ gazının yakıt olarak kullanılmasındaki en büyük sıkıntı depolanmasındaki verimin yetersizliğidir (Zhang ve ark., 2006). Hidrojen yakıtlı araçlarda, hidrojenin güvenli üretimi, taşınması ve yeterli miktarda depolanabilmesi önemlidir.

$\mathrm{Bu}$ nedenle yüksek hidrojen depolama kapasitesine sahip olan sodyum bor hidrürler, hidrojen depolama ortamı olarak büyük önem kazanmıştır. Sodyum bor hidrür, metanolde bozunurken üretilen hidrojenin yarısının bor hidrürden diğer yarısının ise metanolden karşılanmaktadır. Ancak sodyum bor hidrürden hidrojen elde edilirken Eşitlik 1'de belirtilen reaksiyona göre ortamda katalizörlerin kullanılması gerekmektedir (Ramya ve ark., 2013; Yan ve ark., 2015; Sahiner ve Demirci, 2017).

$$
\mathrm{NaBH}_{4}+4 \mathrm{CH}_{3} \mathrm{OH} \rightarrow \mathrm{NaB}\left(\mathrm{OCH}_{3}\right)_{4}+4 \mathrm{H}_{2}
$$

Kullanılan katalizör platin $(\mathrm{Pt})$, rutenyum $(\mathrm{Ru})$, vb. değerli metaller olması durumunda katalizör üretimi maliyetinin pahalı olmasından dolayı her geçen gün farklı metotlar uygulanarak daha ekonomik ve etkin katalizörler sentezlenmeye çalışılmaktadır. Sentezlenen katalizörler arasında destekli katalizörler yaygın olarak kullanılmaktadır ve bu tür katalizörlerin sentezinde en çok kullanılan maddelerden birisi de aktif karbondur. Aktif karbonlar; tarımsal atık, odun, turba, mangal kömürü, kemik, hindistan cevizi kabuğu, pirinç kabuğu, findık kabuğu ve yağ ürünlerinden elde edilen karbonların çeşitli işlemlerden geçirilerek aktive edilmesiyle elde edilmektedirler (Ekinci ve ark., 2013). İşlenen tarım ürünlerinin atıklarının değerlendirilerek aktif karbon gibi katma değeri yüksek ürünlerin üretilmesi, ekonomik anlamda ülke gelişimine katkı sağlayacağı gibi, çevre kirliliğinin kontrol altına alınmasında da önemli rol oynayacaktır. Bu nedenle, bu tür destek maddelerin katalizörlerde kullanılması ve bu destek maddelerin tarımsal atıklardan elde edilmesi oldukça önem arz etmektedir. Literatürlerde; fındık kabuğu (Lewicka,
2017), pamuk sapı (Badie ve ark., 2009) ve palamut kabuğundan (Şahin ve Saka, 2013) aktif karbon eldesi üzerine birçok çalışma bulunmaktadır. Siirt yöresinde yapılan çalışmada ise, yörede yetiştirilen fistık çeşidinin kabuklarının değerlendirilmesi sonucu destek maddesi olarak kullanılabilecek aktif karbon üretilmiş ve bu aktif karbonun yüksek yüzey alanına sahip olduğu belirlenmiştir (Kaya ve ark., 2018). Bu araştırma sonucunda, Siirt yöresinde yetiştirilen ve tarımsal atık olarak nitelendirilen Siirt fistığı kabuğunun işlenerek farklı uygulama alanlarında kullanımının önü açılmıştır.

Bu çalışmada da, Siirt fıstığg kabuğundan elde edilen aktif karbon kullanılarak, destekli Co-B katalizörü üretimi öngörülmüş ve bu katalizör varlığında sodyum borhidrür $\left(\mathrm{NaBH}_{4}\right)$ metanoliz deneylerinin etkinlikleri incelenmiştir. Daha sonra, deneyler sonucundaki verilerin değerlendirilmesi sonucu teorik olarak reaksiyon modellenmesi yapılmıştır.

\section{Materyal ve Yöntem}

Deneysel çalışmalarda gaz ölçümü için kullanılan sistem Şekil 1'de verilmiştir. Sistem reaksiyon kabı, gaz toplama ünitesi ve sıcaklık kontrolü için kullanılan bir termostattan oluşmaktadır. Bu ünitede, gerçekleştirilen reaksiyon sonucu elde edilen $\mathrm{H}_{2}$ gazı miktarı zamana bağlı kaydedilerek grafikleri çizilmiştir. Aktif karbon destekli Co-B katalizörü sentezlenirken ise; ilk etapta Kaya ve ark. (2018) tarafından Siirt fistığı kabuğu kullanılarak elde edilen aktif karbon, aynı prosese göre sentezlenmiştir. Daha sonra $3.6 \mathrm{~g}$ aktif karbon üzerine $1 \mathrm{~g} \quad \mathrm{CoNO}_{3} \cdot 6 \cdot \mathrm{H}_{2} \mathrm{O}$ (Kobalt Nitrat Hegzahidrat) $50 \mathrm{~mL}$ su içerisinde çözündürülerek eklenmiş ve karışım oda sıcaklığında 24 saat boyunca $\mathrm{Co}^{2+}$, 1 aktif karbon üzerine adsorbe olması için oda sıcaklığında bekletilmiştir.

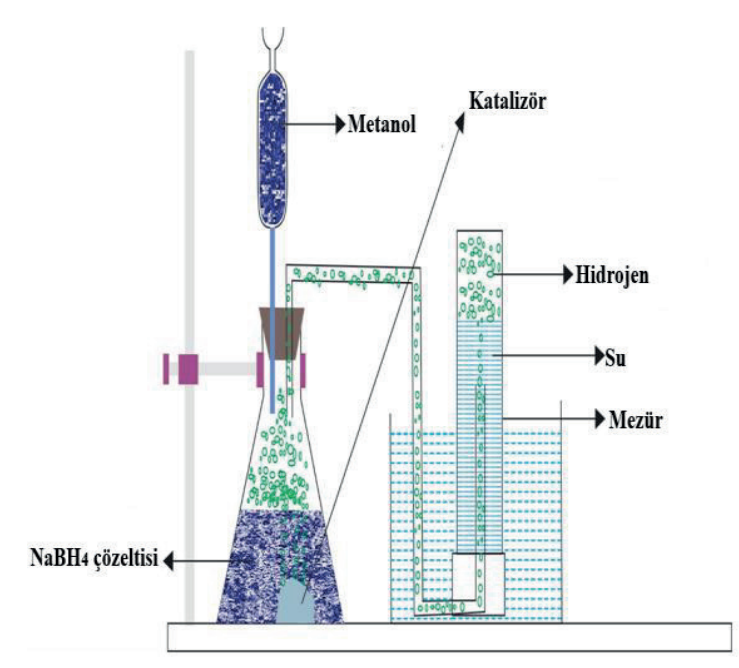

Şekil 1. Reaksiyon düzeneği 
Sonrasında bu karışım süzülerek saf su ile yıkanmış ve $80{ }^{\circ} \mathrm{C}$ sicaklikta etüvde 4 saat kurumaya bırakılmıştır. İndirgenme işlemi için ise bu kuruyan karışımın üzerine $20 \mathrm{~mL}$ su eklenerek karışım disperse edilmiş ve azot gazı varlığında \% 5'lik 20 mL'lik $\mathrm{NaBH}_{4}$ çözeltisi yavaş yavaş eklenerek katalizörün indirgenmesi sağlanmıştır. İndirgenme gerçekleştikten sonra elde edilen aktif karbon destekli Co-B katalizörü santrifüj yardımıyla süzülmüş, daha sonra $3 \mathrm{kez}$ deiyonize su ile yıkanarak 4 saat inert ortamda $120{ }^{\circ} \mathrm{C}$ 'de etüvde kurumaya bırakılmıştır. En son olarak kurutulan aktif karbon destekli Co-B katalizörünün oksitlenmesini engellemek amacıyla kapalı ortamda muhafaza edilerek deneysel çalışmalarda kullanıma hazır hale getirilmiştir (Xu ve ark., 2011).

\section{Bulgular ve Tartışma}

Deneysel çalışmalarda aşağıda belirtilen parametreler incelenmiş olup, bu parametrelerin hidrojen üretim hızına etkileri incelenmiştir.

\section{1. Çözücü ortam etkisi}

Çalışmada, ilk olarak $30{ }^{\circ} \mathrm{C}$ 'de $0.025 \mathrm{~g} \mathrm{NaBH}_{4}$ içeren 10 mL'lik çözelti (metanol, su ve metanolsu karışımı) $\quad 0.1 \quad \mathrm{~g}$ katalizör varlığında bozundurulmuş olup, zamana bağlı hidrojen miktarlarının değişim grafiği Şekil 2'de verilmiştir. Şekilde görüldüğü gibi su-metanol (1:1) çözücü ortamında hidrojen üretim hızının düştüğü, sadece su çözücü ortamında hızın daha yüksek olduğu görülmektedir. Ancak sodyum borhidrürün metanol

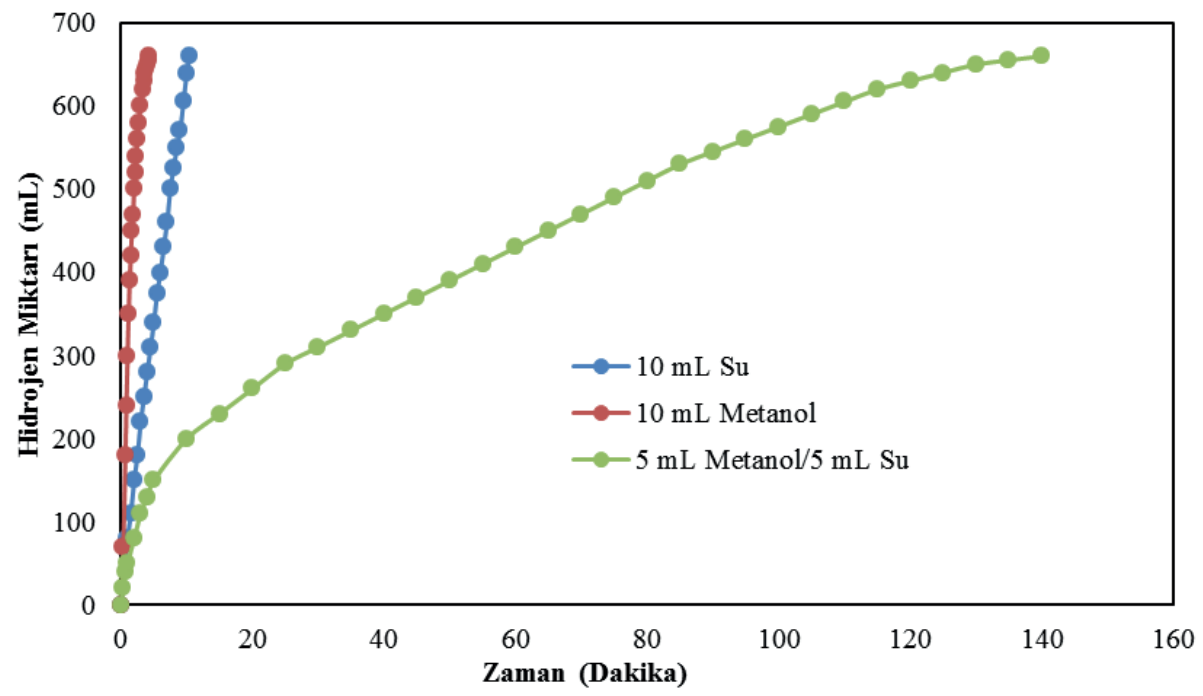

Şekil 2. Farklı çözücü ortamlarında $0.025 \mathrm{~g} \mathrm{NaBH}_{4}$ içeren çözeltinin hidrojen üretim hızının zamanla değişimi* *: $\mathrm{T}=30^{\circ} \mathrm{C}, \mathrm{Vçöz} .=10 \mathrm{~mL}$, mkat $=0.1 \mathrm{~g}$ Katalizör

içerisindeki hidrojen üretim hızının, hem su hem de su-metanol çözücü ortamına göre daha yüksek olmasından dolayı bundan sonraki deneylerimize çözücü ortamı olarak sadece metanol varlığında devam edilmiştir.

\subsection{Katalizör etkisi}

Sodyum borhidrürün bozunması katalizör kontrollü reaksiyonlardır. Katalizör olmadan reaksiyon oldukça yavaş yürümekte ve daha sonra durmaktadır. $\mathrm{Bu}$ nedenle çalışmanın ikinci aşamasında farklı katalizör miktarlarının $\mathrm{NaBH}_{4}$ çözeltisi üzerindeki etkisi incelenmiştir. Katalizör etkinliği incelenirken aynı sıcaklık ve $\mathrm{NaBH}_{4}$ konsantrasyonu varlığında farklı katalizör miktarları kullanılmış olup, hidrojen üretim miktarının zamanla değişimi Şekil 3 'te verilmiştir.

Şekil 3'ten de görüleceği gibi, katalizör miktarı arttıkça hidrojen üretim hızı da artmaktadır. Burada reaksiyon hızının artış nedeni; katalizörün etkin olduğu aktif bölgelerin, katalizör miktarıyla doğru orantılı olarak artmasından kaynaklanmaktadır. Ortamda bulunan katalizör miktarının artmasıyla, sodyum borhidrür daha fazla temas yüzeyine sahip olacağından reaksiyon süresi kısalarak, reaksiyon hızının arttığı görülmektedir. Şekil 3'ten de görüleceği üzere, aynı sodyum borhidrür konsantrasyonuna sahip çözeltilerden $0.2 \mathrm{~g}$ katalizör kullanılarak gerçekleştirilen deney, yaklaşık 1.7 dakikada tamamlanırken, $0.05 \mathrm{~g}$ katalizör kullanılarak gerçekleştirilen deney 7.5 dakikada tamamlanmıştır. Bu iki değer arasında kullanılan katalizör miktarları $(0.1 \mathrm{~g}$ ve $0.15 \mathrm{~g})$ ise reaksiyon tamamlanma süreleriyle doğru orantıl1 olacak şekilde artarak 4.3 dakika ile 2.8 dakikada sonlanmaktadır. Böylece bu reaksiyonun katalizör kontrollü bir reaksiyon olduğunu ve katalizör 


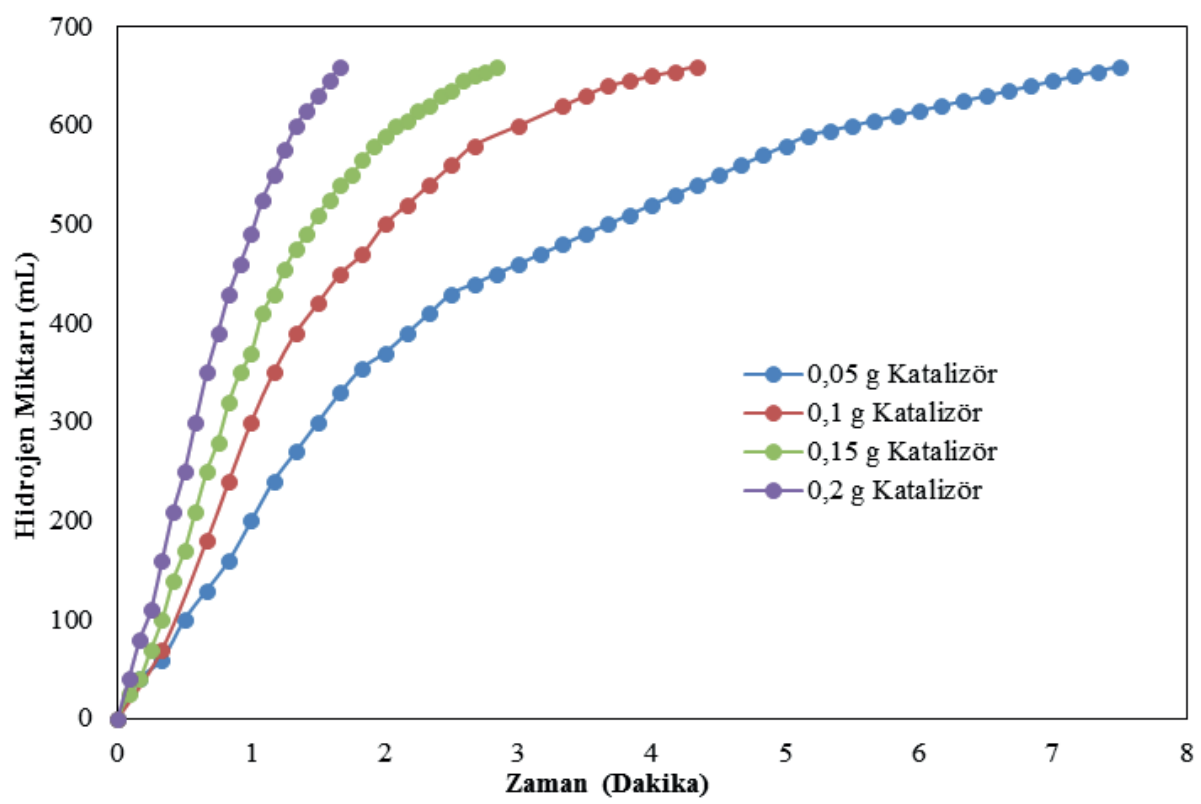

Şekil 3. Aktif karbon destekli Co-B katalizörünün farklı miktarlarınınsodyum bor hidrürün bozunmasına etkisi* *: \% $0.25 \mathrm{NaBH}_{4}$, Vçöz. $=10 \mathrm{~mL}$ Metanol, $\mathrm{T}=30^{\circ} \mathrm{C}$

miktarına bağlı olarak hızın arttığını da söylemek mümkündür.

\section{3. $\mathrm{NaBH}_{4}$ etkisi}

$\mathrm{Bu}$ aşamada, $\mathrm{NaBH}_{4}$ konsantrasyonu dışındaki diğer parametreler sabit tutularak deneylerimiz gerçekleştirilmiş olup, elde sonuçlar Şekil 4'te verilmiştir. Şekil 4'te görüleceği gibi, $\mathrm{NaBH}_{4}$ konsantrasyonu arttıkça genel olarak reaksiyon hızının da arttığını görmek mümkündür. Ancak
\% $\quad 0.5 \quad \mathrm{NaBH}_{4}$ içeren çözeltide, katalizörün reaksiyon hızını belirgin bir şekilde arttırmasının yanı sıra üretilen hidrojen miktarını da arttırdığı görülmektedir. Daha düşük konsantrasyona sahip olan diğer $\mathrm{NaBH}_{4}$ çözeltilerinde ise hidrojen üretim hızının oransal bir şekilde düştüğü ve konsantrasyona bağlı olarak elde edilen hidrojen miktarlarının da düştüğü görülmektedir. Kısacası sabit sıcaklık ve sabit katalizör miktarı varlığında sodyum borhidrür miktarı arttıkça hidrojen üretim hızı ve elde edilen hidrojen miktarı artmaktadır.

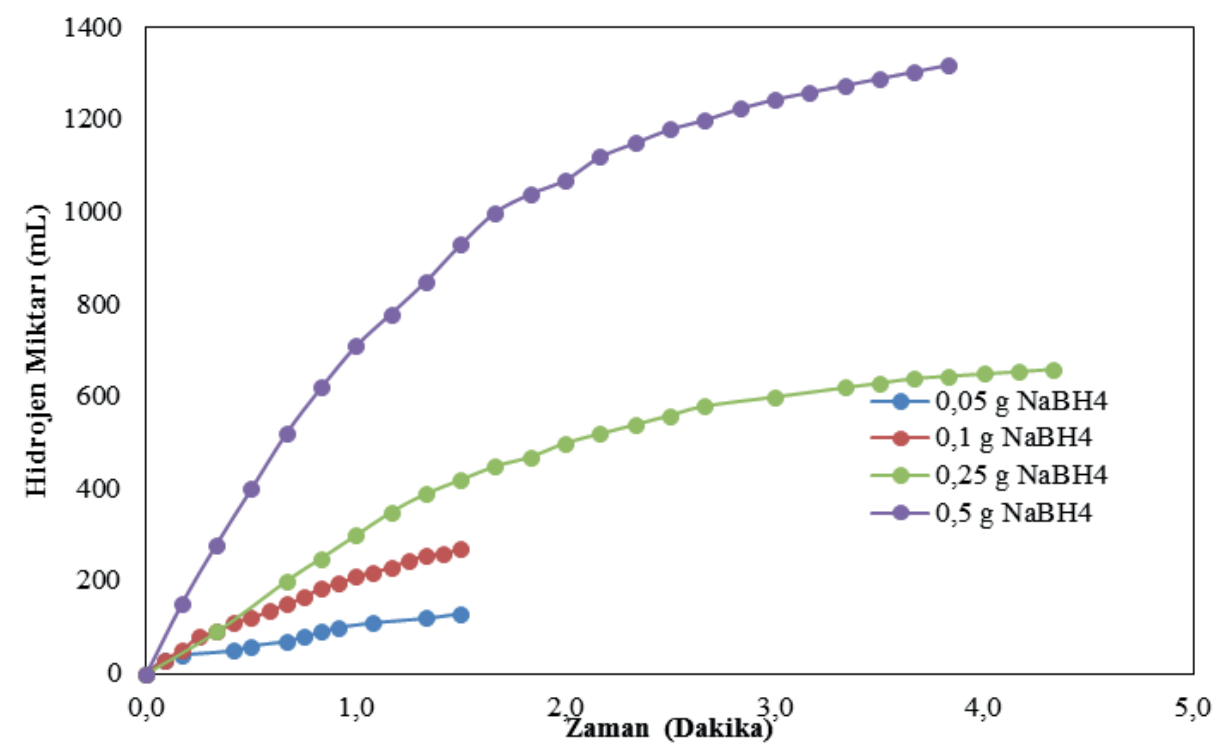

Şekil 4. Farklı sodyum bor hidrür konsantrasyonlarının aktif karbon destekli Co-B katalizör varlığında hidrojen üretim hızına etkisi*

$$
\text { ": mkat }=0.1 \mathrm{~g}, \mathrm{Vçöz.}=10 \mathrm{~mL}, \mathrm{~T}=30^{\circ} \mathrm{C}
$$




\subsection{Sıcaklık etkisi}

Son aşamada ise önceki deneylerden elde edilen verilerden yola çıkılarak belirlenen deney koşullarının, farklı sıcaklıktaki etkinlikleri incelenmiş olup, elde edilen sonuçlar Şekil 5'te verilmiştir.

Şekil 5'ten de görüleceği üzere; sodyum borhidrürün bozunmasına sıcaklığın etkisinin, üretilen hidrojen hacminde artışa neden olmasının yanı sıra reaksiyon hızını da arttırarak reaksiyon süresini kısaltmaktadır. Sicaklık ile yapılan çalıșmalarda, $60{ }^{\circ} \mathrm{C}$ 'deki reaksiyon yaklaşık 2.2 dakikada tamamlanırken, $30{ }^{\circ} \mathrm{C}$ 'de gerçekleştirilen reaksiyon süresinin 4.3 dakikayı bulduğu görülmüștür. Böylece sıcaklık artışının, katalizör kontrollü sodyum borhidrürün bozunma reaksiyonlarının hızını arttırarak süreyi kısalttığını söylemek mümkündür.

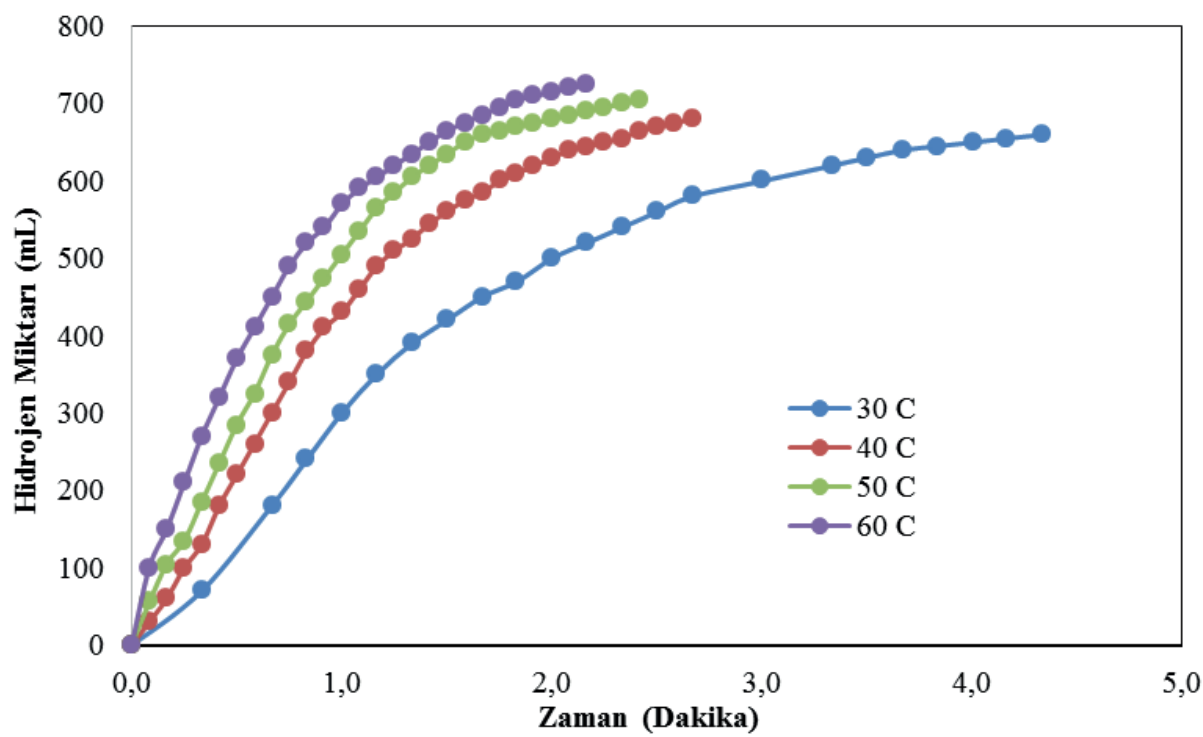

Şekil 5. Farklı sıcaklıklarda sodyum bor hidrür çözeltisinin aktif karbon destekli Co-B katalizör varlığında hidrolizinin zamanla değişimi* ${ }^{*}$ *: mkat= $0.1 \mathrm{~g}, \% 0.25 \mathrm{NaBH}_{4}$, Vçöz. $=10 \mathrm{~mL}$

\subsection{Reaksiyon modellemesi}

Katalizör kontrollü reaksiyonlar genelde üç basamakta gerçekleşmektedir. Bunlar, sırasıyla; adsorpsiyon basamağ1, yüzey reaksiyonu basamağ ve desorpsiyon basamaklarından oluşmaktadır. Bu basamaklardan biri reaksiyonu kontrol etmekte ve reaksiyon hızını da, bu kontrol eden basamak belirlemektedir. $\mathrm{Bu}$ yüzden reaksiyon modellemesinde, reaksiyon kontrol basamağın belirlenmesi gerekmektedir. Bu kısımda, belirlenen kontrol basamağından sonra deneysel çalışmalardan elde edilen sonuçlardan yararlanılarak ampirik bir formül elde edilmiştir (Ahlström-Silversand ve Odenbrand, 1999; Sandelin ve ark., 2006). Elde edilen ampirik formül sayesinde deneysel sonuçlar ile teorik sonuçlar karşılaştırılmış olup, reaksiyon modellemesi için gerekli açıklamalar aşağıda yapılmıştır.

$$
\begin{aligned}
& \mathrm{NaBH}_{4}+4 \mathrm{CH}_{3} \mathrm{OH} \rightarrow \mathrm{NaB}\left(\mathrm{OCH}_{3}\right)_{4}+4 \mathrm{H}_{2} \\
& \text { (A) (B) } \rightarrow \quad \text { (C) }
\end{aligned}
$$

$\mathrm{A}+\mathrm{S} \rightarrow$ A.S (Adsorbsiyon Basamağı)

$$
\begin{aligned}
& \mathrm{A}+\mathrm{S} \rightarrow \text { E.S }+\mathrm{C} \text { (Yüzey Reaksiyon Basamağı) } \\
& \text { E.S } \rightarrow \text { E }+\mathrm{S} \text { (Desorbsiyon Basamağı) }
\end{aligned}
$$

Eşitlik 3'te S, katalizör aktif bölgesini ifade etmektedir.

Yukarıda reaksiyon basamakları sırasıyla verilmiştir. Aşağıda ise sırasıyla adsorpsiyon, yüzey reaksiyonu ve desorpsiyon basamağının reaksiyon hız denklemleri Eşitlik 6-8'de verilmiştir.

$$
\begin{aligned}
& r A=k A \cdot\left[c A \cdot c V-\frac{c A \cdot S}{k A}\right] \\
& r S=k S \cdot\left[c A \cdot S-\frac{c V \cdot c E \cdot S}{k S}\right] \\
& r D=k D \cdot\left[c E \cdot S-\frac{c E \cdot c V}{k D}\right]
\end{aligned}
$$

Eşitlik 6-8'de $r A$, adsorpsiyon hız basamağını; $r S$, yüzey reaksiyon hiz basamağını; $r D$, desorbsiyon hız basamağını ifade etmektedir.

Çözümleme yaparken reaksiyon kontrolünün, yüzey reaksiyonuna bağlı olduğu kabul edilerek aşağıda belirtildiği gibi (Eşitlik 9 ve 10) (3) adsorpsiyon ve desorpsiyon basamağının reaksiyon hızının 0 olduğu gösterilmektedir. 


$$
\begin{aligned}
& \frac{r A}{k A}=0 \Longrightarrow c A . S=k A \cdot c A \cdot C V \\
& \frac{r D}{k D}=0
\end{aligned} \quad \begin{aligned}
& c E \cdot S=k E \cdot c E \cdot c V
\end{aligned}
$$

Daha sonra; Eşitlik 6'daki denklemde, Eşitlik 9 ve Eşitlik 10 denklemleri yerine yerleştirilerek Eşitlik 11 denklemi elde edilmiştir.

$$
r S=k 1\left[c A-\frac{c E \cdot c V}{k 2}\right]
$$

Eşitlik 11'de; $k 1=k S . k A . c V, k 2=(k A . k S) / k E)$ olarak kabul edilmiştir.

Boş bölgeler balansı Eşitlik 12'deki gibi ifade edilmiştir.

$$
c T=c V+c A . S+c E . S
$$

Eşitlikler düzenlendiğinde; Eşitlik 12'deki denklemde, Eşitlik 9 ve Eşitlik 10 denklemleri yerleştirilerek $c V$ bulunur ve Eşitlik 11'deki denklemde yerine konularak ampirik denklem (Eşitlik 13) bulunur.

$$
r S=\frac{k 3, c A}{1+k A \cdot c A+k E \cdot c E}
$$

Eşitlik 13'te, $k 3=k S . k A . c T$ olarak kabul edilmiştir.

Eşitlik 13'teki denklem kullanılarak bulunan ampirik formülün doğruluğunu teyit etmek için önceden elde edilmiş olan deney sonuçları, bulunan bu denklem ile MathCAD kullanılarak teorik olarak tekrar elde edilmiştir. Deneysel ve teorik sonuçlar üstüste çakıştırılmış ve sonuç Şekil 6'da verilmiştir.

Şekil 6'dan da görüleceği gibi hesaplanan teorik sonuçların (ra, A), deneysel sonuçlarla (r, B) örtüşmesinde \% 99.9 başarı sağlanmıştır. Bu sonuç, elde edilen ampirik formülün deneysel sonuçları birebir temsil ettiğini göstermektedir. Deney yapmadan ampirik formülle bulunan sonuçların yüksek başarıyla örtüşmesi, deney maliyetini azaltmakta ve kisa sürede deney sonuçlarının elde edebileceği anlamına gelmektedir. Ayrıca reaksiyonun, yüzey reaksiyonu kontrollü olduğunu da söylemek mümkündür.

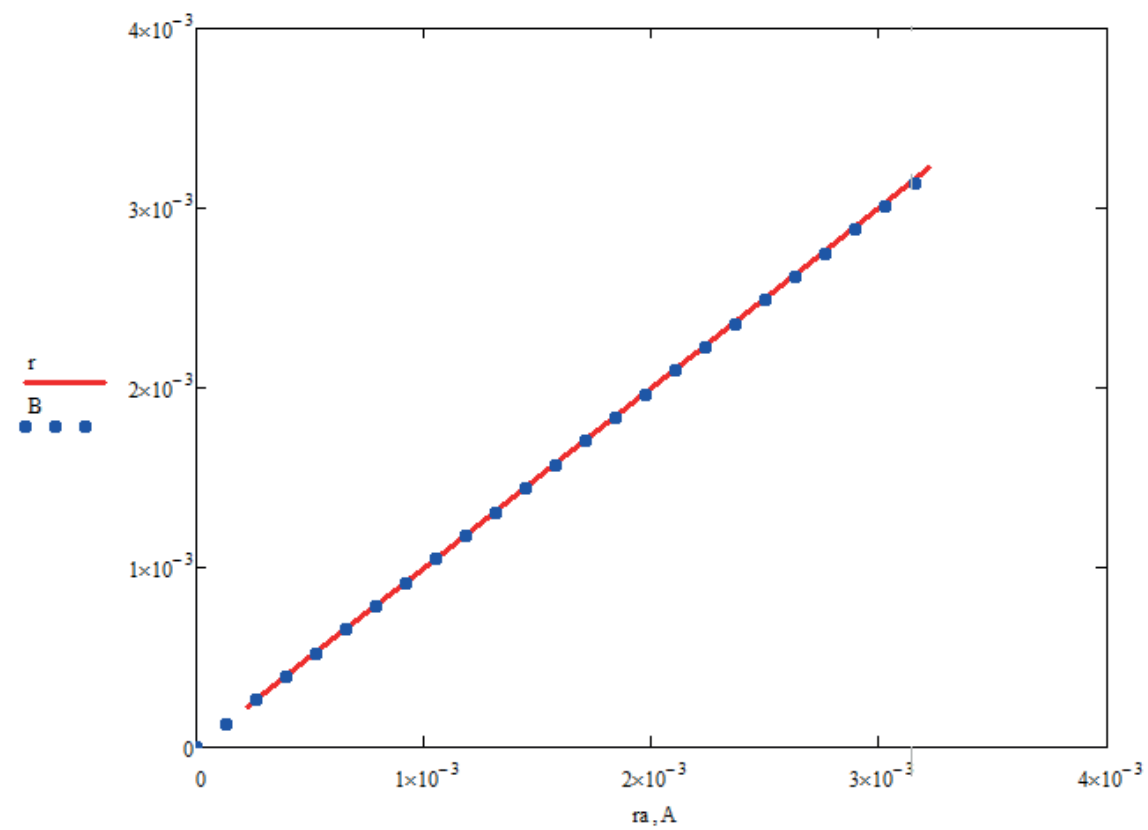

Şekil 6. Deneysel sonuçlarla teorik sonuçların eşleştirilmesi*

*: mkat $=0.1 \mathrm{~g}, \% 0.25 \mathrm{NaBH}_{4}$, Vçöz. $=10 \mathrm{~mL}, \mathrm{~T}=30^{\circ} \mathrm{C}$

\section{Sonuçlar}

Sodyum borhidrürün metanolizi için yüksek performanslı katalizörlerin geliştirilmesinde tarımsal atıkların kullanılması birçok açıdan önem arzetmektedir. Bunların en başında tarımsal atıkların çevreye zararlarının engellenmesi, atık konumunda nitelendirilen maddelere ticari değer kazandırılarak ekonomik olarak değerlendirilmesi ve bu tip destek maddeler kullanılarak katalizör veriminin arttırılması gibi birçok etken bulunmaktadır. Burada destek maddesi olarak kullanılan aktif karbonun, atık olarak nitelendirilen Siirt fistığı kabuğundan elde edilmesi, hem bölgenin kalkınması adına hem de gelecekteki çevre ve enerji sorunlarını çözmek adına önemli bir adım olmuștur. Yüksek yüzey alanına sahip olması daha fazla $\mathrm{Co}^{2+}$ adsorplaması anlamına gelmektedir 
ve böylece birim alana düşen katalizör miktarının daha yüksek seviyelere çıkmasını sağlamaktadır. $\mathrm{Bu}$ da $\mathrm{NaBH}_{4}$ 'ün metanolizde kullanılan Siirt fistığı kabuğundan elde edilmiş aktif karbon destekli Co$\mathrm{B}$ katalizörünü daha nitelikli hale getirmektedir. $\mathrm{Bu}$ etkileri $\mathrm{NaBH}_{4}$ 'ten hidrojen eldesindeki deneylerin genel olarak 0 ile 6 dakika gibi kısa bir sürede gerçekleşmesinden de anlamak mümkündür. Bunun yanı sıra deneyler sonucundan yola çıkılarak belirlenen ampirik formül bundan sonra gerçekleştirilecek deneylerle ilgili bilgileri teorik olarak elde etmemizi sağlayacaktır. Böylece çalışmamızda matematiksel olarak hesaplanamayan parametrelerin belirlenmesinde ve herhangi bir deney yapmadan maliyetsiz olarak deney sonuçlarına ulaşma imkanı sağlanılmış olacaktır. Diğer bir yandan tarımsal atıklardan elde edilen aktif karbonun destekli katalizör üretiminde kullanımının başarılı sonuçlar gösterdiği saptanmıştır. Bunun yanı sıra $\mathrm{Co}^{2+}$ metaline alternatif olarak daha değersiz metaller kullanılarak Siirt fistığ 1 kabuğundan elde edilen aktif karbon ile destekli katalizör sentezlenmesi önerilmektedir. Son olarak Siirt fistığının dışında Türkiye'de yetişen diğer tarımsal ürünlerin atıklarından da destek maddesi üretilerek etkinliklerinin incelenmesi yerinde olacaktır.

\section{Kaynaklar}

Ahlström-Silversand, A.F., Odenbrand, C.U.I., 1999. Modelling catalytic combustion of carbon monoxide and hydrocarbons over catalytically active wire meshes. Chemical Engineering Journal, 73(3): 205216.

Badie, S., Girgisa, E., Smith, M., 2009. Pilot production of activated carbon from cotton stalks using H3PO4. Journal of Analytical and Applied Pyrolysis, 86(1): 180-184.

Ekinci, A., Sahin, O., Saka, C., Avci, T., 2013. The effects of plasma treatment on electrochemical activity of Co-W-B catalyst for hydrogen production by hydrolysis of $\mathrm{NaBH}_{4}$. International Journal of Hydrogen Energy, 38(35): 15295-15301.
İzgi, M.S., Şahin, Ö., Erhan, O., Horoz, S., 2017. Metanolde sentezlenen Co-B katalizörün sodyum hidrolizi üzerine etkisi. I $\breve{g} d ı r$ Üniversitesi Fen Bilimleri Enstitüsü Dergisi, 7(4): 151-160.

Kaya, M., Şahin, Ö., Saka, C., 2018. Preparation and TG/DTG, FT-IR, SEM, BET surface area, iodine number and methylene blue number analysis of activated carbon from pistachio shells by chemical activation. International Journal of Chemical Reactor Engineering, 16(2), doi.org/10.1515/ijcre2017-0060.

Lewicka, K., 2017. Activated carbons prepared from hazelnut shells, walnut shells and peanut shells for high $\mathrm{CO}_{2}$ adsorption. Polish Journal of Chemical Technology, 19(2): 38-43.

Ramya, K., Dhathathreyan, K., Sreenivas, J., Kumar, S., Narasimhan, S., 2013. Hydrogen production by alcoholysis of sodium borohydride. International Journal of Energy Research, 37(14): 1889-1895.

Sahiner, N., Demirci, S., 2017. Natural microgranular cellulose as alternative catalyst to metal nanoparticles for $\mathrm{H}_{2}$ production from $\mathrm{NaBH}_{4}$ methanolysis. Applied Catalysis B: Environmental, 202: 199-206.

Sandelin, F., Oinas, P., Salmi, T., Paloniemi, J., Haario, H., 2006. Dynamic modelling of catalytic liquidphase reactions in fixed beds-kinetics and catalyst deactivation in the recovery of anthraquinones. Chemical Engineering Science, 61(14): 4528-4539.

Şahin, Ö., Saka, C., 2013. Preparation and characterization of activated carbon from acorn shell by physical activation with $\mathrm{H}_{2} \mathrm{O}-\mathrm{CO}_{2}$ in two-step pretreatment. Bioresource Technology, 136: 163-168.

Xu, D., Wang, H., Guo, Q., 2011. Catalytic behavior of carbon supported Ni-B, Co-B and Co-Ni-B in hydrogen generation by hydrolysis of $\mathrm{KBH}_{4}$. Fuel Processing Technology, 92(8): 1606-1610.

Yan, K., Li, Y., Zhang, X., Yang, X., Zhang, N., Zheng, J., 2015. Effect of preparation method on $\mathrm{Ni}_{2} \mathrm{P} / \mathrm{SiO}_{2}$ catalytic activity for $\mathrm{NaBH}_{4}$ methanolysis and phenol hydrodeoxygenation. International Journal of Hydrogen Energy, 40(46): 16137-16146.

Zhang, J., Fisher, T.S., Gore, J.P., Hazra, D., Ramachandran, P.V., 2006. Heat of reaction measurements of sodium borohydride alcoholysis and hydrolysis. International Journal of Hydrogen Energy, 31(15): 2292-2298. 